\title{
Rethinking the Fear Circuit: The Central Nucleus of the Amygdala Is Required for the Acquisition, Consolidation, and Expression of Pavlovian Fear Conditioning
}

\author{
Ann E. Wilensky, ${ }^{1 \star}$ Glenn E. Schafe, ${ }^{2 \star}$ Morten P. Kristensen, ${ }^{1}$ and Joseph E. LeDoux ${ }^{1}$ \\ ${ }^{1}$ W. M. Keck Foundation Laboratory of Neurobiology, Center for Neural Science, New York, New York 10003, and ${ }^{2}$ Department of Psychology and \\ Interdepartmental Neuroscience Program, Yale University, New Haven, Connecticut 06520
}

In the standard model of pavlovian fear learning, sensory input from neutral and aversive stimuli converge in the lateral nucleus of the amygdala (LA), in which alterations in synaptic transmission encode the association. During fear expression, the LA is thought to engage the central nucleus of the amygdala $(\mathrm{CE})$, which serves as the principal output nucleus for the expression of conditioned fear responses. In the present study, we reexamined the roles of LA and CE. Specifically, we asked whether CE, like LA, might also be involved in fear learning and memory consolidation. Using functional inactivation methods, we first show that CE is involved not only in the expression but also the acquisition of fear conditioning. Next, we show that inhibition of protein synthesis in CE after training impairs fear memory consolidation. These findings indicate that CE is not only involved in fear expression but, like LA, is also involved in the learning and consolidation of pavlovian fear conditioning.

Key words: amygdala; central nucleus; consolidation; fear conditioning; muscimol; anisomycin

\section{Introduction}

The amygdala has long been implicated in the learning and memory of emotional events, especially through studies of pavlovian fear conditioning, a procedure in which an initially emotionally neutral, conditioned stimulus (CS) is paired with an aversive, unconditioned stimulus (US). Although early studies of amygdala circuitry implicated the central nucleus of the amygdala $(\mathrm{CE})$ in the expression of conditioned fear responses (Kapp et al., 1979; Pascoe and Kapp, 1985; LeDoux et al., 1988; Hitchcock and Davis, 1991), subsequent research showed that the lateral nucleus of the amygdala (LA) was critical for the learning, or acquisition, of fear conditioning (LeDoux et al., 1990b; Campeau and Davis, 1995; Amorapanth et al., 2000). This work has led to a widely accepted model of fear conditioning (but see Cahill et al., 1999) in which information about the CS and US converges in the LA, producing alterations in synaptic transmission in LA neurons (LeDoux, 2000; Blair et al., 2001; Maren, 2001). Subsequent exposure to the CS activates LA neurons that connect with CE, both directly and by way of the adjacent basal nucleus (Pitkanen et al., 1995). Neurons in CE then signal to hypothalamic and brainstem

Received Nov. 7, 2003; accepted 0ct. 3, 2006.

This research was supported in part by National Institute of Mental Health Grants K05 MH067048, R01 MH46516, and R37 MH38774 (J.E.L.) and F31 MH63612 (A.E.W.). This work was also supported by a grant from the W. M. Keck Foundation to New York University. We thank Karim Nader for critical comments on this manuscript, Jeremiah Martino for assistance with the behavioral experiments, Yu Zhou for assistance with making electrodes, and David Bush for assistance with the behavioral analysis.

${ }^{*}$ A.E.W. and G.E.S. contributed equally to this work.

Correspondence should be addressed to Dr. Joseph E. LeDoux, Center for Neural Science, New York University, Room 809, 4 Washington Place, New York, NY 10003. E-mail: ledoux@cns.nyu.edu.

DOI:10.1523/JNEUROSCI.4316-06.2006

Copyright $\odot 2006$ Society for Neuroscience $\quad 0270-6474 / 06 / 2612387-10 \$ 15.00 / 0$ regions that control the defensive and autonomic emotional responses to fear (LeDoux et al., 1988; Hitchcock and Davis, 1991; Shi and Davis, 1999).

Although much evidence implicates the LA as an essential locus of learning and memory of fear conditioning, the role of $\mathrm{CE}$ is less thoroughly understood. Interestingly, the CE has many of the same characteristics that originally implicated the LA as a critical site for fear learning. The CE, like LA, is the recipient of projections from the auditory cortex (McDonald, 1998) and the auditory thalamus (LeDoux et al., 1987; Turner and Herkenham, 1991), raising the possibility that it receives direct CS input from the auditory system. It also receives somatosensory (US) information from parietal and insular cortices (McDonald, 1998) and serves as the endpoint for the spino(trigemino)-parabrachioamygdaloid pathway, which transmits pain information from the spinal cord (Bernard and Besson, 1990; Jasmin et al., 1997). Furthermore, as in LA, high-frequency stimulation of thalamic inputs induces an NMDA receptor (NMDAR)-dependent longterm potentiation (LTP) in the CE (Samson and Paré, 2005), fear conditioning modifies neurophysiological responses of CE neurons (Applegate et al., 1982; Pascoe and Kapp, 1985), and lesions of the CE impair fear conditioning (Kapp et al., 1979; Young and Leaton, 1996; Goosens and Maren, 2001; Nader et al., 2001).

Although the convergence of CS and US inputs and traininginduced changes in neural activity are consistent with the notion that $\mathrm{CE}$ is involved in fear learning, these findings alone are not sufficient to support this conclusion. Complicating this question further is the fact that CE is required for the expression of conditioned fear responses (Kim and Davis, 1993). As a result, lesion studies cannot distinguish a role for $\mathrm{CE}$ in fear acquisition from that of a role in fear expression. Furthermore, one could argue 
that neurophysiological changes induced in CE by fear conditioning are not attributable to plasticity in CE but instead simply reflect a passive "readout" of changes that have occurred upstream in the LA.

In the present study, we reexamined the role of $\mathrm{CE}$ in fear conditioning using local, anatomically restricted infusions of the $\mathrm{GABA}_{\mathrm{A}}$ agonist muscimol and of the protein synthesis inhibitor anisomycin. Our findings indicate an important role for CE not only in fear expression but also in the learning and consolidation of fear conditioning. Collectively, these findings suggest that the emotional learning and memory system is more distributed within the amygdala than previously appreciated.

\section{Materials and Methods}

Subjects. Adult male Sprague Dawley rats obtained from Hilltop Laboratory Animals (Scottdale, PA) were housed individually in plastic Nalgene cages with ad libitum food and water and maintained on a $12 \mathrm{~h}$ light/dark cycle. All procedures were conducted in accordance with the National Institutes of Health Guide for the Care and Use of Laboratory Animals and were approved by the New York University Animal Care and Use Committee.

Surgery. Rats were anesthetized with either sodium pentobarbital (40 $\mathrm{mg} / \mathrm{kg}$, i.p.) or a mixture of ketamine $(75-100 \mathrm{mg} / \mathrm{kg})$ and xylazine $(10$ $\mathrm{mg} / \mathrm{kg})$, along with buprenorphine- $\mathrm{HCl}(0.02 \mathrm{mg} / \mathrm{kg})$ as an analgesic. Guide cannulas (22 gauge; Plastics One, Roanoke, VA) (Walker and Davis, 1997; Schafe and LeDoux, 2000), fitted with 28 gauge internal cannulas that extended $1.5 \mathrm{~mm}$, were lowered into LA $[-2.8 /-3.0$ anteroposterior (AP), 5.3 mediolateral (ML), and 8.0 dorsoventral (DV)] or CE (-2.8 AP, 4.3 ML, and 8.5 DV] using coordinates from the atlas of Paxinos and Watson (1997). The cannulas were fixed to skull screws using cranioplastic cement (Plastics One). Twenty-eight gauge obturators, cut to extend $0.5 \mathrm{~mm}$ from the guides, were inserted to prevent clogging.

Intracranial infusions. For infusions, internal infusion cannulas were attached to $1.0 \mu \mathrm{l}$ Hamilton syringes via polyethylene tubing, which was backfilled with sesame oil. A small air bubble separated the oil from the infusate. While held in the experimenter's lap, rats were infused bilaterally at a rate of $0.15 \mu \mathrm{l} / \mathrm{min}$ using an infusion pump. Cannulas were left in place for an additional $1 \mathrm{~min}$ to allow drug diffusion away from the cannula tip. For all studies, unless stated otherwise, $0.2 \mu \mathrm{l}$ was infused into each nucleus.

Fear acquisition experiments. On day 1, rats were habituated to the training and testing apparatus for a minimum of 10-15 min and to dummy cannula removal and replacement. On the training day (day 2), rats received pretraining infusions into CE or LA of either artificial CSF (ACSF) $(0.2 \mu \mathrm{l} / \mathrm{side})$ or muscimol $(0.02 \mu \mathrm{g}$ in $0.2 \mu \mathrm{l} /$ side $)$. After $5-10$ $\mathrm{min}$, rats were placed in a dimly lit conditioning chamber (chamber A) (model E10-10; Coulbourn Instruments, Allentown, PA) and conditioned with two pairings of a $30 \mathrm{~s}, 5 \mathrm{kHz}, 75 \mathrm{~dB}$ tone that coterminated with a 1.0 s., $1.5 \mathrm{~mA}$ footshock [intertrial interval (ITI) of $120 \mathrm{~s}$ ].

Rats were tested on day 3, $24 \mathrm{~h}$ after training, with three presentations of the CS (ITI of $100 \mathrm{~s}$ ). Testing was performed in a distinct chamber (chamber B) (model ENV-001; Med Associates, E. Fairfield, VT), which was brightly lit and consisted of a flat black plastic floor that had been washed with a peppermint soap. The amount of time (in seconds) spent freezing during each CS was then measured off-line from the videotape. Freezing was defined as the absence of all movement with the exception of that required for the animal to breathe. The $30 \mathrm{~s}$ period preceding the first tone was also scored to measure any generalization of fear to the context.

Fear consolidation experiments. Rats were habituated to the conditioning and testing apparatus for a minimum of 10-15 min and to dummy cannula removal and replacement. For muscimol inactivations, training consisted of a single pairing of a $30 \mathrm{~s}, 5 \mathrm{kHz}, 75 \mathrm{~dB}$ tone paired with a $1.0 \mathrm{~s}$, $1.5 \mathrm{~mA}$ footshock in chamber A, followed immediately by an infusion of either $\operatorname{ACSF}(0.2 \mu \mathrm{l} /$ side $)$ or muscimol $(0.02 \mu \mathrm{g}$ in $0.2 \mu \mathrm{l} /$ side $)$. Testing was the same as described in the acquisition protocol in chamber B. For experiments examining the effects of protein synthesis inhibition, rats were trained with a single trial consisting of a $30 \mathrm{~s}, 5 \mathrm{kHz}, 75 \mathrm{~dB}$ tone that coterminated with a $1.0 \mathrm{~s}, 2 \mathrm{~mA}$ shock in chamber A. Immediately after training, rats received infusions of either $0.2 \mu \mathrm{l}$ of ACSF or anisomycin (12.5 $\mu \mathrm{g}$ in $0.2 \mu \mathrm{l}$ of ACSF per side) at a rate of $0.15 \mu \mathrm{l} / \mathrm{min}$ (for details of how we dissolved anisomycin in aqueous solution, see Schafe and LeDoux, 2000). Rats were then tested for short-term memory (STM) and long-term memory (LTM) in chamber B. STM testing took place $4 \mathrm{~h}$ after training and infusion. Rats were tested with three presentations of the CS. The amount of time spent freezing during each CS was then measured off-line from videotape. The $30 \mathrm{~s}$ period preceding the first tone was also scored to measure any baseline freezing to context. LTM testing took place $\sim 24 \mathrm{~h}$ after training in the same manner as for STM.

Fear expression experiment. After habituation and conditioning, rats received infusions of either ACSF $(0.2 \mu \mathrm{l} /$ side $)$ or muscimol $(0.02 \mu \mathrm{g}$ in $0.2 \mu \mathrm{l} / \mathrm{side}$ ) 5-10 min before an expression test consisting of three CS presentations. Rats were then retested drug free $24 \mathrm{~h}$ later with three CS presentations to confirm that the infusions only affected expression and to control for any long-term effects of muscimol infusion.

Behavioral data analysis. All behavioral data were analyzed with Student's $t$ test or an ANOVA, and post hoc analysis was performed using Scheffé's or Duncan's post hoc tests. Differences were considered significant if $p<0.05$.

Electrophysiological recordings. Urethane-anesthetized rats $(1-1.5 \mathrm{~g} / \mathrm{kg}$, i.p.) were placed in a stereotaxic frame, and appropriate areas of the skull and dura over the left hemisphere were removed. A guide cannula aimed at CE (for details, see above, Surgery) and a bipolar stimulating electrode (1.0 $\mathrm{mm}$ tube to tip) aimed at auditory thalamus [medial division of the medial geniculate nucleus/posterior intralaminar nucleus (MGm/PIN); $-5.6 \mathrm{AP}, 2.9 \mathrm{ML}$, and 6.9 DV] were lowered. An injector filled with ACSF $(0.2 \mu \mathrm{l})$ or muscimol $(0.02 \mu \mathrm{g}$ in $0.2 \mu \mathrm{l}$ of ACSF $)$, connected to an infusion pump (for details, see above, Intracranial infusions), was placed in the guide. Subsequently, a glass pipette $(0.5-8 \mathrm{M} \Omega$ ) filled with $150 \mathrm{~mm}$ sodium acetate with $2.5 \%$ pontamine sky blue ( $\mathrm{pH} 8.0$ ) was lowered into the LA using stimulation of MGm/PIN as a guide. Throughout the experiment, field potentials produced by stimulation of the MGm/PIN $(300-600 \mu \mathrm{A})$ were evoked every $5 \mathrm{~s}$. In each experiment, we set the level of stimulation within the dynamic range to allow observation of both potential increases and decreases in amplitude of the response.

After achieving a stable potential, evoked potentials were collected for $10 \mathrm{~min}$, the last $2 \mathrm{~min}$ of which were used as a baseline measurement (for a total of 24 evoked potentials). Rats were then given an intra-CE infusion in the same manner as in the behavioral studies, except that the infusion cannula remained in the guide to prevent inadvertent movement of the recording electrode. Field potentials after the first infusion were recorded for $20 \mathrm{~min}$, which encompassed the time from infusion to training in our behavioral experiments. The infusion cannula was then removed, refilled with a larger volume of ACSF $(1 \mu \mathrm{l})$ or a larger volume and higher concentration of muscimol $(1 \mu \mathrm{g} / \mu \mathrm{l}$ in $1 \mu \mathrm{l}$ of ACSF), and replaced into the guide. A new baseline was recorded for $10 \mathrm{~min}$, followed by infusion of the larger dose and volume of muscimol. After infusion, field potentials evoked by thalamic stimulation were recorded for an additional $20 \mathrm{~min}$. At the end of each experiment, the LA recording site was marked with a iontophoretic injection of pontamine sky blue $(-19$ $\mu \mathrm{A}, 7-8 \mathrm{~min}$ ), and the rat was perfused for histological staining to determine electrode and cannula placements.

Using Spike2 (version 4.01; Cambridge Electronic Design, Cambridge, UK), the latencies for the 24 evoked potentials in each relevant time period (for details, see Results) were measured at the peak of the first negativity (in millivolts), producing an average \pm SE latency for each 2 min period. We then measured both the area under the curve and the maximal amplitude for each field potential at averaged latency.

After subtracting the appropriate baseline from each experimental period to determine the average changes from baseline for each animal, we used a repeated-measures ANOVA to determine whether vehicle or drug infusions led to significant changes in the amplitude of field evoked potentials. Separate analyses were performed for both small and large infusions.

Histology. To verify cannulas and electrode placements, rats were anesthetized with an overdose of chloral hydrate $(250 \mathrm{mg} / \mathrm{kg}$, i.p. $)$ and per- 
a.
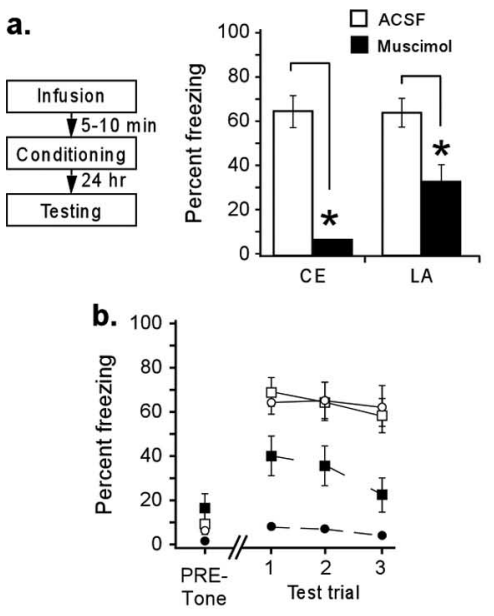

c.
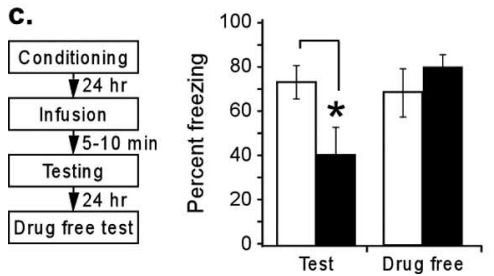

d.

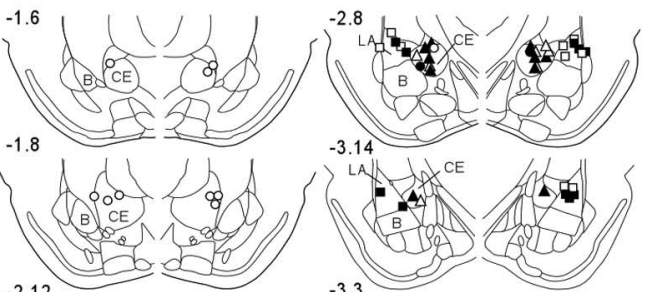

$-2.12$

$-3.3$

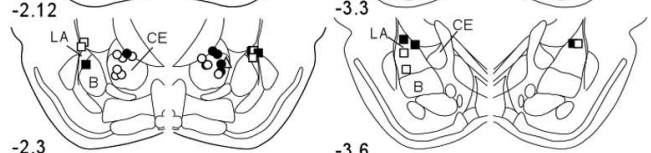

$-2.3$

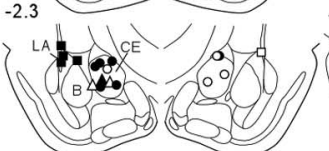

$-3.6$
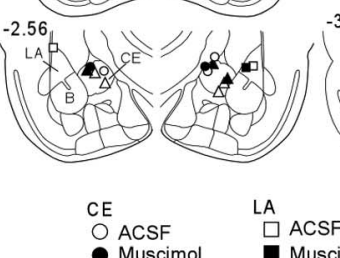

$\mathrm{CE}$
-

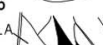

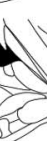

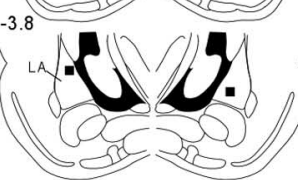

Muscimol

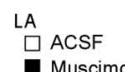

Figure 1. The role of CE in the acquisition of auditory fear conditioning. $\boldsymbol{a}$, Procedural outline and mean \pm SE percentage freezing during $C S$ presentation averaged across all tone trials. Freezing scores after functional inactivation of either CE or LA were significantly decreased from control groups $\left({ }^{*} p<0.05\right)$. The average freezing after functional inactivation of CE was also significantly different from that of LA ( $p<0.05)$. $\boldsymbol{b}$, Mean \pm SE percentage freezing per group during each tone trial. $\boldsymbol{c}$, Procedural outline for functional inactivation of CE during expression and mean \pm SE percentage freezing to $C S$ presentation averaged across all tone trials during testing and $24 \mathrm{~h}$ later, drug free. Although muscimol significantly decreased freezing $\left({ }^{*} p<0.05\right)$, muscimoltreated animals did not differ from controls when retested drug free. $\boldsymbol{d}$, Cannula tip placements for all animals included in analysis (drawings adapted from Paxinos and Watson, 1997). Numbers on the left refer to posterior to bregma in millimeters. B, Basal nucleus.

fused transcardially with $10 \%$ buffered Formalin. The brains were postfixed in 30\% sucrose in Formalin and subsequently blocked and sectioned on a cryostat at $50 \mu \mathrm{m}$. Alternate sections were stained for Nissl $(0.5 \%$ cresyl violet or $0.25 \%$ thionin $)$ and acetylcholinesterase to assist with identification of electrode placements. Sections were then coverslipped with Permount and examined under light microscopy for cannula and electrode placements.

\section{Results}

Pretraining functional inactivation of CE impairs fear acquisition, whereas pretesting inactivation impairs fear expression

Previous studies from our laboratory have shown that reversible functional inactivation of the entire amygdala using the $\mathrm{GABA}_{\mathrm{A}}$ antagonist muscimol impairs acquisition of fear conditioning (Wilensky et al., 2000). Those experiments, however, were unable to distinguish the contribution of individual amygdala nuclei in fear learning. Here, we reversibly and selectively inactivated LA or $\mathrm{CE}$ during acquisition of conditioned fear. We reasoned that, if $\mathrm{CE}$ is only involved in the expression of fear responses and not in fear learning, then inactivation of CE during acquisition should leave the subsequent expression of learned fear responses intact. Alternatively, if both LA and CE are necessary for fear learning, then selective inactivation of either nucleus should impair fear learning.

Rats with guide cannulas aimed at either LA or CE received infusions of ACSF $(0.2 \mu \mathrm{l} /$ side $)$ or muscimol ( $0.02 \mu \mathrm{g}$ in $0.2 \mu \mathrm{l}$ of ACSF per side). This dose was lowered from the standard concentration used in the literature by a factor of 10 , as well as reduced in volume, to limit the radius of diffusion to within the
Expression

$\triangle \mathrm{ACSF}$

$\triangle$ Muscimo approximate radius of CE (Martin, 1991; Helmstetter and Bellgowan, 1994; Sanders and Shekhar, 1995; Muller et al., 1997; Paxinos and Watson, 1997; Walker and Davis, 1997; Wilensky et al., 2000; Edeline et al., 2002). After 5-10 min, the rats were conditioned with two CS-US pairings. The next day ( $\sim 24 \mathrm{~h}$ later $)$, we tested the rats for retention of conditioned fear, using freezing behavior during tone presentation as a measure of the strength of emotional learning (Fig. 1a). Cannula placements are presented in Figure $1 d$. We note here that rats in these and in all subsequent experiments were only included in analysis if both tips were located in, or directly on the edge of, the targeted nucleus.

\section{Muscimol infusion into LA impairs}

fear acquisition

Figure $1 a$ shows mean \pm SE percentage freezing averaged across all three test tone presentations for groups receiving muscimol infusion into either CE or LA. In support of the hypothesis that LA is a critical site of fear learning, selective reversible functional inactivation of the LA disrupted fear acquisition relative to ACSFinfused controls $\left(F_{(1,20)}=7.10 ; p<0.05\right)$, an effect found in all three trials (Fig. $1 b$ ). The average amount of freezing in muscimol-infused animals (40\%) differs from that of our previous work (20\%) (Wilensky et al., 2000), a difference consistent with the lower dose infused and the stronger behavioral protocol used in this study. The baseline freezing scores during the $30 \mathrm{~s}$ period before CS onset did not differ from controls $\left(t_{(20)}=\right.$ $0.71)$, indicating that the learned fear did not generalize across contexts but was specific to the tone (Fig. $1 b)$. There was also a significant effect for trial $\left(F_{(2,40)}=3.76 ; p<0.05\right)$, most likely attributable to extinction because we found no drug by trial interaction $\left(F_{(2,40)}=0.57\right)$.

\section{Muscimol infusion into CE impairs fear acquisition}

When we reversibly inactivated CE before fear conditioning (Fig. $1 a, b)$, we found qualitatively similar results as when we inactivated LA. CE-inactivated animals showed strong impairments in fear learning, contradicting the model of $\mathrm{CE}$ as an output-only structure. There was a significant effect of $\operatorname{drug}\left(F_{(1,19)}=31.7 ; p<0.001\right)$ over all three trials, with no significant effect on freezing during the pretone period $\left(t_{(19)}=1.02\right)$ or drug by trial interaction $\left(F_{(2,38)}=\right.$ $0.015)$. Interestingly, unlike LA, there was no effect of trials $\left(F_{(2,38)}=\right.$ $0.81)$. Presumably, this occurred because inactivation of $\mathrm{CE}$ almost completely abolished freezing. In fact, using the same dose of muscimol, functional inactivation of CE had a significantly stronger effect on acquisition than inactivation of LA (Duncan's test, $p<0.05$ ), possibly attributable to the longer anteroposterior extent of LA (Paxinos and Watson, 1997).

\section{Muscimol infusion into CE impairs fear expression}

In a final experiment, we functionally inactivated CE before testing to confirm the role of CE in fear expression. Previous studies that have examined the role of CE during fear expression have 
used either permanent lesions or inactivations of the entire amygdala (Helmstetter, 1992; Helmstetter and Bellgowan, 1994; Muller et al., 1997). Here, we reexamined this question by using localized, selective infusions of muscimol into CE.

Figure $1 c$ shows the behavioral results of inactivating CE before fear expression. After muscimol infusion into the CE, freezing behavior was significantly impaired during all CS presentations compared with controls $\left(F_{(1,12)}=15.5 ; p<\right.$ $0.05 ; n=4$ each group). The ANOVA showed no effect of trials $\left(F_{(3,36)}=0.59\right)$ or of drug by trial interaction $\left(F_{(3,36)}=0.27\right)$. In contrast, when rats were tested drug free $24 \mathrm{~h}$ later, they froze at levels comparable with controls $\left(F_{(1,12)}=1.02\right)$ (Fig. 1c), also with no effect of trials $\left(F_{(2,24)}=0.30\right)$ or drug by trial interaction $\left(F_{(2,24)}=0.29\right)$.

These findings support the idea that $\mathrm{CE}$ has a specific role not only in the normal circuitry underlying fear expression but also in the circuitry underlying the acquisition of fear.

\section{Impaired fear learning after intra-CE} infusion of muscimol is not attributable to state-dependent learning or to impaired reactivity to the shock US

To examine whether our observed memory impairment after intra-CE infusion of muscimol might be attributable to statedependent learning or to blunted reactivity to the shock US, we ran two additional experiments. Rats with indwelling CE cannulas (Fig. 2e) were infused with either ACSF $(n=5)$ or muscimol $(0.02 \mu \mathrm{g} /$ side; $0.2 \mu \mathrm{l} ; n=10)$ and trained as in the previous experiments. On the next day, rats infused with ACSF before training received a second infusion of ACSF $(0.2 \mu \mathrm{l})$ before a retention test (ACSFACSF; $n=5$ ). Rats infused with muscimol before training were divided into two groups: one receiving ACSF before the retention test $(0.2 \mu \mathrm{l}$; Musc-ACSF; $n=5)$ and the other receiving muscimol $(0.2 \mu \mathrm{l}$; Musc-Musc; $n=5)$. As in our previous experiment, the retention test consisted of three tone CS presentations (ITI of $100 \mathrm{~s}$ ). Relative to the ACSF-ACSF group, both the Musc-ACSF and Musc-Musc groups exhibited impaired retention (ACSFACSF vs Musc-ACSF, $t_{(8)}=2.31, p<0.05$; ACSF-ACSF vs Musc-Musc, $t_{(8)}=3.23, p<0.05$ ) (Fig. $2 b$ ). Furthermore, no differences emerged between the two groups that received muscimol on the training day $\left(t_{(8)}=0.211 ; p>0.05\right)$. Accordingly, the memory deficit observed in the first experiment cannot be attributed to state-dependent learning.

To rule out the possibility that intra-CE infusion of muscimol might have produced memory deficits as the result of impaired reactivity to the shock US, we randomly assigned animals from the Musc-ACSF and Musc-Musc groups to a second experiment 1 week later (Fig. $2 d$ ). In that experiment, rats received infusions of either $\operatorname{ACSF}(0.2 \mu \mathrm{l})$ or muscimol $(0.02 \mu \mathrm{g} / 0.2 \mu \mathrm{l}) \sim 10 \mathrm{~min}$ before receiving a series of three $1.5 \mathrm{~mA}, 1 \mathrm{~s}$ shocks, each separated by $0.5 \mathrm{~s}$. A series of shocks was used to increase sampling of activity to the shock b.
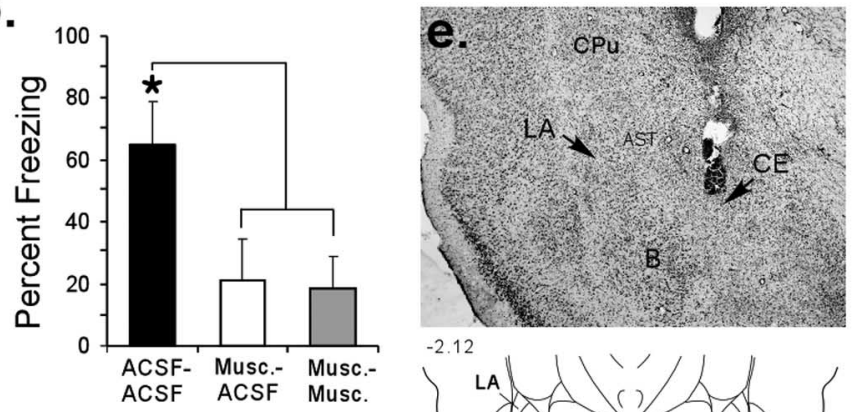

$-2.12$

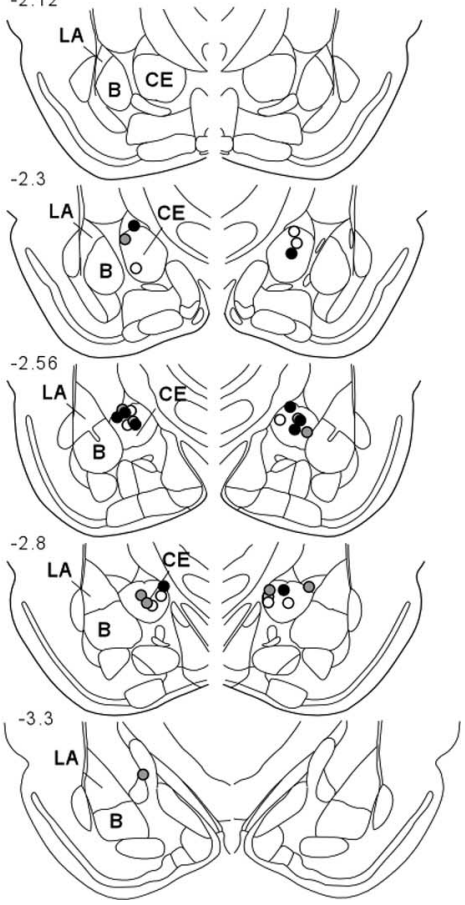

Figure 2. State-dependent and shock reactivity tests. $\boldsymbol{a}$, Experimental protocol. $\boldsymbol{b}$, Mean \pm SE percentage freezing for each group. ${ }^{*} p<0.05$ relative to the ACSF-Musc and Musc-Musc groups. $c$, Mean \pm SE percentage freezing for each group across each trial. $\boldsymbol{d}$, Mean \pm SE movement units before, during, and after the shock US. $\boldsymbol{e}$, Top, Photomicrograph of a representative cannula placement in the CE. Bottom, Cannula tip placements for all animals included in analysis (drawings adapted from Paxinos and Watson, 1997). Numbers on the left refer to posterior to bregma in millimeters. B, Basal nucleus.

US in both groups. The activity of rats in each group was measured automatically during each shock presentation and also for a $3 \mathrm{~s}$ period before and after the series of shock presentations using Coulbourn Instruments activity monitors (model H24-61) that were mounted to the top of the experimental chambers. During shock presentations, both ACSF- and muscimol-treated rats were observed to exhibit normal reactions to the shock, including jumping and vocalizing. Analysis of activity revealed that presentation of the series of shock USs led to an increase in activity relative to the $3 \mathrm{~s}$ baseline period in both the ACSF- and muscimol-infused groups (Fig. 2d). This increase was significant for the muscimol-treated rats $\left(t_{(4)}=\right.$ 2.97; $p<0.05)$ and showed a trend toward significance for the ACSF-treated rats $\left(t_{(4)}=1.89 ; p=0.06\right)$. Furthermore, no differences in total shock reactivity emerged between the two groups $\left(t_{(8)}\right.$ $=0.62 ; p>0.05)$. Thus, it is unlikely that infusions of muscimol into CE produced memory impairments by blunting perception of or reactivity to the shock US.

The behavioral effects of muscimol infusions into $\mathrm{CE}$ are not attributable to diffusion into LA

In our initial set of experiments, we found that selective functional inactivation of CE impaired fear learning. Furthermore, 


\section{a. Large Infusion}

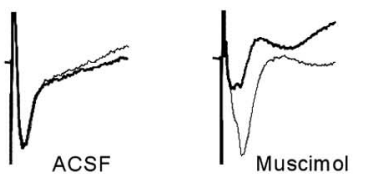

Small Infusion

(Behavioral Dose)

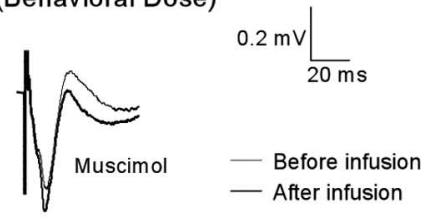

\section{b.}

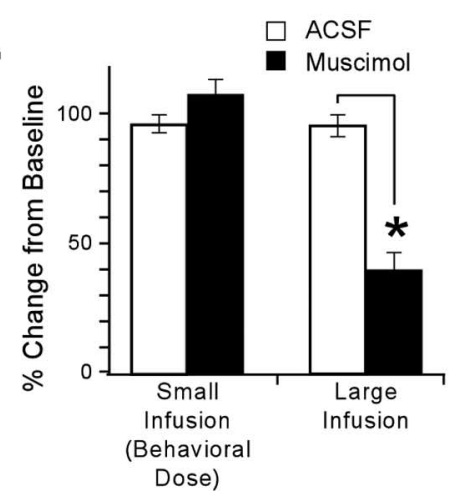

c.

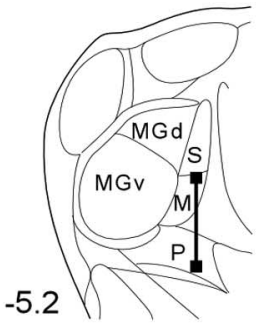

d.

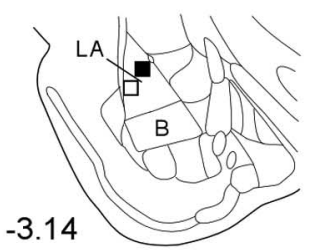

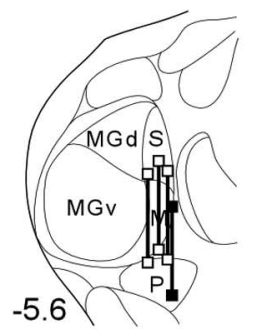
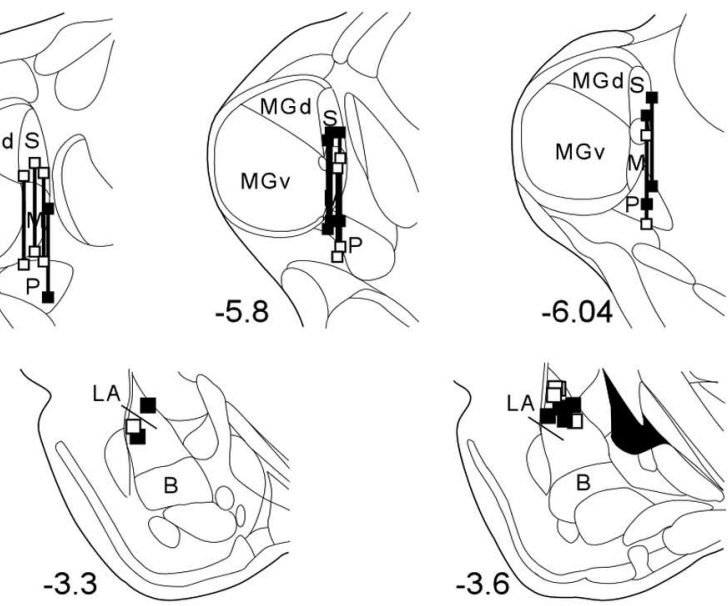

e.

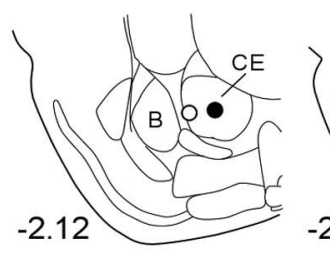

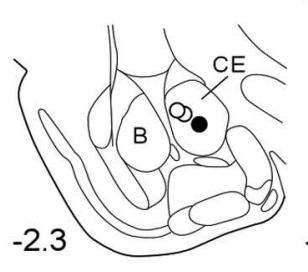
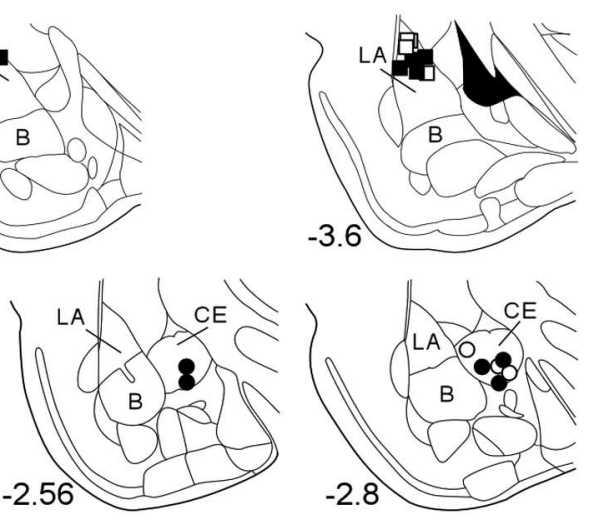

Figure 3. Evoked activity in LA after functional inactivation of CE. $\boldsymbol{a}$, Examples of averaged evoked field potentials before and after infusions. Large infusions of muscimol produced a significant reduction in field potential amplitude and area, whereas small infusions had little effect. $\boldsymbol{b}$, Ratio of the amplitude of the negative-going component after infusions to the baseline amplitude. After large infusions of muscimol designed to spread to LA, the amplitude is observed to be significantly decreased relative to ACSF-infused animals $\left({ }^{*} p<0.001\right)$. However, after infusion of the smaller dose of muscimol used in our behavioral experiments, the field responses in muscimol-infused rats did not differ from that of ACSF-infused rats. $c$, Thalamic electrode placements for all animals included in analysis. MGd, Dorsal division of the medial geniculate nucleus; MGv, ventral division of the medial geniculate nucleus; $M$, medial division of the medial geniculate nucleus; $S$, suprageniculate nucleus; $P$, posterior intralaminar nucleus. $\boldsymbol{d}$, LA recording electrode placements. $\boldsymbol{e}$, CE cannula placements.

infusions of muscimol into CE produced a significantly larger effect on fear learning than infusions into LA. If the drug had spread from CE to LA to produce the effect on fear acquisition, then the resulting memory impairment should have been stronger when muscimol was infused directly into the LA, not weaker.

Nevertheless, to further evaluate the possibility that drug diffusion from CE to LA might account for the effects on fear learning, we examined the effect of muscimol infusion into CE on evoked field potentials in the LA. We stimulated the MGm and the PIN, which convey auditory input to LA (Doron and LeDoux, 1999). Stimulation of these areas produces field potentials in LA, with a characteristic negative-going component of $\sim 5-10 \mathrm{~ms}$, which corresponds to the peak of multiunit activity (Doyère et al., 2003). We recorded thalamic-evoked potentials for $10 \mathrm{~min}$ to ensure a stable baseline. We then infused either ACSF $(0.2 \mu \mathrm{l})$ or the dose and volume of muscimol used in our behavioral experiments $(0.02 \mu \mathrm{g} ; 0.2 \mu \mathrm{l})$ into CE. Because the longest training period in our fear conditioning paradigm (from infusion until the last footshock) lasted $\sim 15 \mathrm{~min}$, we recorded evoked potentials for $20 \mathrm{~min}$ after the infusion to observe any change in LA attributable to diffusion of muscimol from CE that might have occurred during the time course of our behavioral experiments.

After the first baseline and infusion period, we infused a second time, using either a larger volume of ACSF ( $1 \mu \mathrm{l})$ or a larger volume and concentration of muscimol, which would be expected to diffuse into LA $(1 \mu \mathrm{g} / \mu \mathrm{l}$ in $1 \mu \mathrm{l})$. As before, we recorded field potentials in LA for 20 min to observe any changes in LA attributable to muscimol infusion into $\mathrm{CE}$.

Because behavioral training lasted $\sim 3$ min, we sampled 24 potentials for a baseline (the 2 min immediately preceding drug infusion). After each infusion, we collected the potentials during two 2 min time periods corresponding to the timing of the training in the behavioral experiments. Using a repeated-measures ANOVA, we then analyzed the field potential for any changes in amplitude or in area under the curve.

Figure $3 a$ shows an example of field potentials recorded during the baseline period and after infusions for each condition (ACSF, $n=6$; muscimol, $n=7$ ). Only the large infusion of muscimol into CE resulted in a significant change in the amplitude and area of the negative-going component of the potentials in LA. Figure $3 b$ shows the ratio of the amplitude of the negativegoing component before and after the infusions, in which $100 \%$ indicates no change in amplitude. After large infusions of muscimol, the amplitude of LA-evoked field potentials in muscimoltreated animals decreased significantly, as would be expected if muscimol diffused from CE to LA [amplitude, $F_{(1,11)}=33$; area (data not shown), $F_{(1,11)}=33 ; p<0.001$ for both measurements]. Although there was no effect of trials overall (amplitude, $F_{(1,11)}=2.5$; area, $\left.F_{(1,11)}=2.3\right)$, there was a drug by trial interaction for both measurements (amplitude, $F_{(1,11)}=6.0$; area, $F_{(1,11)}$ $=5.4 ; p<0.05)$. These findings show that large doses and vol- 
umes of muscimol, when infused into CE, are capable of spreading to the LA and impairing evoked activity.

In contrast, infusion of the smaller (behavioral) dose and volume of muscimol into $\mathrm{CE}$ had no observable effect on thalamic-evoked field potentials in the LA. Analysis showed no significant change in area $\left(F_{(1,11)}=0.76\right)$ or in amplitude $\left(F_{(1,11)}=1.7\right)$ (Fig. 3a,b). There was also no effect of trials (area, $F_{(1,11)}=0.89$; amplitude, $\left.F_{(1,11)}=0.17\right)$ or any drug by trial interaction (area, $F_{(1,11)}=2.5$; amplitude, $\left.F_{(1,11)}=0.78\right)$. This finding is clearly inconsistent with the hypothesis that infusion of the small dose and volume of muscimol into $\mathrm{CE}$ produced its behavioral effect on fear conditioning by spreading to LA. Rather, these findings imply that LA activity, within the chosen stimulation parameters of the present experiment, is not affected by the smaller dose of muscimol used in our behavioral experiments.

Cannula and electrode placements for the electrophysiology experiment are presented in Figure $3 c-e$. On inspection of the figure, it is clear that our electrode placements in LA were somewhat more posterior than our cannula placements in CE. As such, it remains possible that our infusions of muscimol into CE may have diffused to the most anterior portions of the LA. Accordingly, our neurophysiological findings alone do not provide unequivocal support for the conclusion that muscimol is incapable of diffusing to LA. However, when considered together with our behavioral findings showing that infusions of muscimol into CE produce significantly larger disruptions in fear learning than those in LA, these findings collectively support the conclusion that our behavioral effects are likely attributable to a disruption of activity in CE and are not secondary to diffusion of the drug to the LA.

\section{Posttraining inactivation of CE does not impair fear conditioning}

Although our inactivations of CE took place before acquisition, muscimol is a long-lasting drug that can have behavioral effects for at least $1 \mathrm{~h}$ after infusion (Arikan et al., 2002; Edeline et al., 2002). Previous studies from our laboratory have shown that pretraining but not posttraining inactivation of the LA impairs pavlovian fear conditioning, indicating a role for LA in fear acquisition (Wilensky et al., 2000). However, in other fear learning paradigms, the LA plays a very different role. For example, in tasks such as inhibitory avoidance learning, posttraining inactivation of the LA impairs memory formation (Wilensky et al., 2000), presumably because ongoing activity in LA after training modulates plasticity and memory formation in other brain regions (McGaugh et al., 2000). Thus, it is possible that the effects of inactivation of CE ob- served in the previous experiment are attributable to a modulatory role of that nucleus that takes place after acquisition and that LA is the only nucleus of the amygdala necessary for the initial learning of fear conditioning. Therefore, we inactivated CE immediately after training to determine whether our initial behavioral findings were attributable to effects on learning or modulatory effects of $\mathrm{CE}$ on other brain regions after training.

Figure 4 shows the effect of functional inactivation of CE on the acquisition of auditory fear learning when muscimol is infused immediately after training (for details of the behavioral procedure, see Fig. 4a). We found no significant differences in fear retention in muscimol-infused animals $(n=5)$ compared with controls $(n=6)$ (Fig. $4 b)$. This lack of effect was consistent over all three test CS presentations (Fig. 4c); there was no significant difference of drug $\left(F_{(1,9)}=0.53\right)$, trials $\left(F_{(2,18)}=1.12\right)$, or drug by trial interaction $\left(F_{(2,18)}=0.86\right)$.

Because functional inactivation of $\mathrm{CE}$ only affects acquisition of fear conditioning when infused before, and not after, training, this implies that $\mathrm{CE}$ is necessary during the time of acquisition and is not involved in a posttraining modulatory role. 


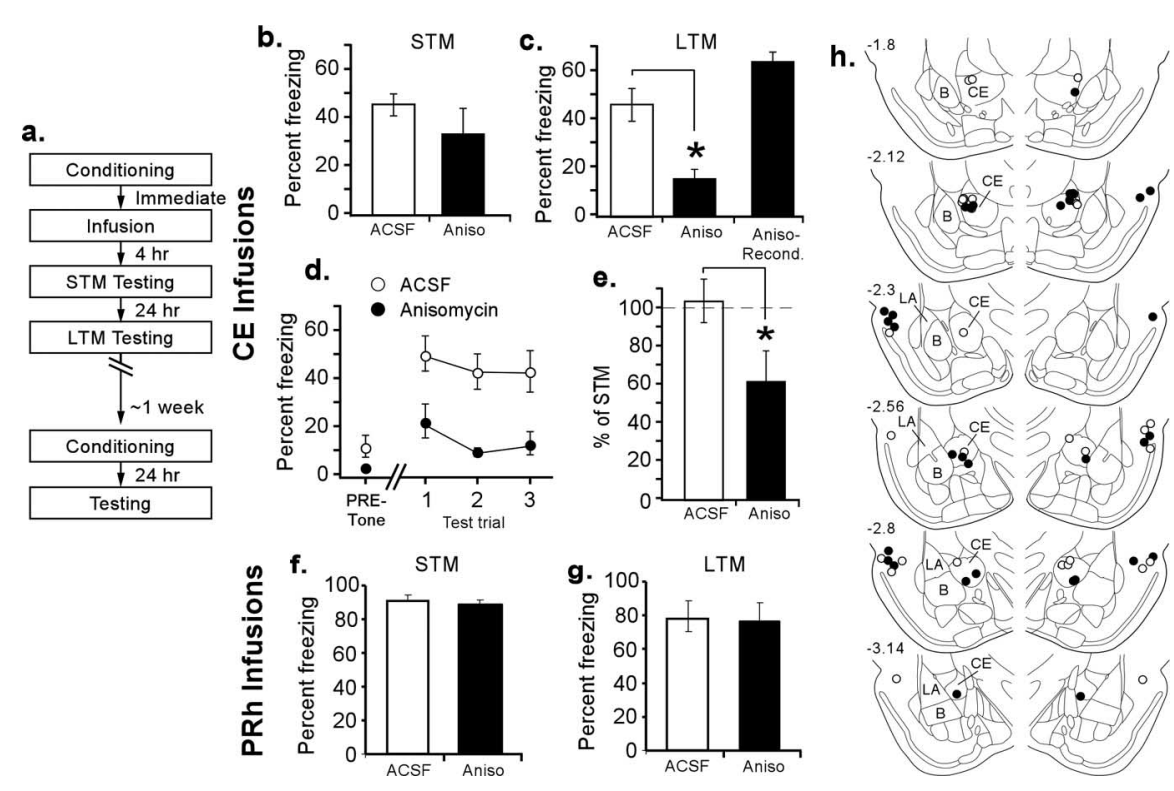

Figure 5. The role of CE in the consolidation of auditory fear conditioning. $\boldsymbol{a}$, Procedural outline. $\boldsymbol{b}$, STM mean \pm SE percentage freezing averaged across all CS presentations. Anisomycin-treated (Aniso) and ACSF-infused animals did not significantly differ. $c$, LTM mean \pm SE percentage freezing averaged across all CS presentations. Intra-CE infusion of anisomycin significantly impaired $\operatorname{LTM}\left({ }^{*} p<0.001\right)$. In contrast, after retraining, animals froze at the same levels as controls. $d$, Mean \pm SE percentage freezing per group during each LTM test CS. All three trials show the same pattern of significance as in $c$. $e$, The LTM to STM ratios show that consolidation is significantly impaired after infusions of anisomycin into CE. ${ }^{*} p<0.01 . \boldsymbol{f}, \boldsymbol{g}$, Mean \pm SE percentage freezing during the STM and LTM tests in rats that received intra-PRh infusion of vehicle or anisomycin. $\boldsymbol{h}$, CE and PRh cannula placements for all animals included in analysis. B, Basal nucleus.

\section{Protein synthesis inhibition in CE impairs fear memory consolidation}

Our initial findings indicate that functional inactivation of $\mathrm{CE}$ during fear conditioning disrupts the acquisition of fear learning, a function previously believed to be limited to the LA. Another function thought to be limited to LA is fear memory consolidation, or the process by which an STM is transformed, over time, into stable LTM (Schafe et al., 2001).

Current models of fear conditioning postulate that the CS-US pairing leads to the activation of various intracellular signaling cascades in LA that engage the transcription of genes and subsequent synthesis of the relevant proteins needed for LTM formation (Stevens, 1994; Alberini et al., 1995). Therefore, to identify whether a neural structure is involved in consolidation and/or storage of a memory, studies commonly use disruption of either protein synthesis or the intracellular signaling cascades leading to protein synthesis and examine whether the formation of LTM is also disrupted. For example, intra-LA infusion of inhibitors of protein or RNA synthesis impairs the consolidation of fear conditioning, implying that the LA is necessary for the consolidation and subsequent encoding of the fear memory (Bailey et al., 1999; Schafe and LeDoux, 2000).

If CE plays an active role in the consolidation of fear memories, as it appears to do in fear learning, we would reasonably expect that disruption of protein synthesis in CE would affect LTM of fear conditioning. Accordingly, we infused the protein synthesis inhibitor anisomycin into CE immediately after fear learning to examine the role of $\mathrm{CE}$ in the consolidation of fear conditioning.

Rats were conditioned with one CS-US pairing and then infused with $\operatorname{ACSF}(0.2 \mu \mathrm{l} /$ side; $n=11)$ or anisomycin $(12.5 \mu \mathrm{g}$ in $0.2 \mu \mathrm{l} / \mathrm{side} ; n=9$ ) into CE immediately after the training trial (Fig. $5 a$ ). After 4 h, rats were presented with three CSs and scored for freezing as a measure of STM, which occurs independently of protein synthesis (Schafe and LeDoux, 2000). This controlled for nonspecific effects of the protein synthesis inhibitor on memory. Rats were then retested $24 \mathrm{~h}$ later for LTM to reveal any deficits in the consolidation of the memory.

Figure $5 b$ shows mean \pm SE percentage freezing averaged across all three test tone presentations during the STM test, Figure $5 c$ shows mean \pm SE percentage freezing averaged across all three test tone presentations during the LTM test, and Figure $5 d$ shows all three LTM CS presentations. Freezing during the STM test after anisomycin infusions did not significantly differ from controls $\left(F_{(1,15)}=3.19\right)$, nor was there an interaction effect. There was an effect of trials, in which trial 3 differed significantly from trial 1 , presumably attributable to extinction $\left(F_{(2,30)}=3.40 ; p<\right.$ $0.05)$. In contrast, after protein synthesis inhibition, freezing during the LTM test was significantly impaired during all three CS presentations $\left(F_{(1,18)}=13.23 ; p<\right.$ $0.01)$. The baseline freezing scores during the $30 \mathrm{~s}$ period before CS onset during both STM and LTM testing did not differ from controls (STM, $t_{(15)}=1.25$; LTM, $\left.t_{(18)}=1.78\right)$ (Fig. $5 d$ ), indicating that fear did not generalize across contexts but was specific to the tone. Finally, after LTM testing, animals were retrained drug free to make sure that anisomycin did not produce nonspecific permanent damage to $\mathrm{CE}$, which might account for the impairment in LTM. As shown in Figure $5 c$, retrained animals retained the ability to associate the CS and US. Animals acquired fear conditioning to the same levels as initially acquired by ACSF-infused rats after one-trial conditioning $\left(t_{(18)}=2.1\right)$.

Another, perhaps more persuasive, way to measure the effect of a drug treatment on memory consolidation is to look at the ratio of freezing during the LTM test to that during the STM test. Because we know from our results that STM remained unaffected after protein synthesis inhibition, if LTM was likewise unaffected, the converted ratio of the freezing scores should approach $100 \%$. In contrast, if LTM is impaired, the ratio will drop. A comparison of the LTM/STM freezing ratio of ACSF- and anisomycin-treated animals (Fig. 5e) shows that control animals show the expected behavioral ratio of $100 \%$, whereas anisomycin-treated animals show a significant drop in value $\left(t_{(18)}=2.93\right.$; $\left.p<0.01\right)$. This measure clearly shows the change in freezing from STM to LTM.

Finally, we performed two additional experiments to examine the specificity of protein synthesis inhibition in CE and the consolidation deficit. The first experiment controlled for possible long-term effects of drug infusion into CE. Although animals can be retrained effectively, it is possible that anisomycin has a nonspecific behavioral effect, such as an increase in overall activity levels, at $24 \mathrm{~h}$ after infusion, which might compete with the freezing response and thus prevent an accurate measure of fear retention. To address this possibility, we infused rats with ACSF (0.2 $\mu \mathrm{l} ; n=3)$ or anisomycin (25 $\mu \mathrm{g}$ in $0.2 \mu \mathrm{l} ; n=3) 24 \mathrm{~h}$ before training and tested STM $1 \mathrm{~h}$ after training (data not shown). This is approximately the same amount of time as between posttrain- 
ing infusions and LTM in the initial experiment. Analysis of STM freezing showed no impairment (vehicle, $65 \pm 30 \%$; anisomycin, $50 \pm 10 ; t_{(4)}=0.56 ; p>0.05$ ), which implies that the effects of anisomycin are not attributable to a long-lasting, nonspecific effect of the drug on the animals' ability to freeze.

The second experiment examined the possibility that drug diffusion from CE to LA was responsible for the memory impairments observed after anisomycin infusion. To address this question, we infused a comparable volume of vehicle $(0.2 \mu \mathrm{l} ; n=6)$ or anisomy$\operatorname{cin}(12.5 \mu \mathrm{g}$ in $0.2 \mu \mathrm{l} ; n=6)$ just lateral to the LA in the perirhinal cortex (PRh). In contrast to our findings after infusion into CE, infusion of anisomycin into the PRh had no effect on fear memory consolidation. Rats displayed intact STM $4 \mathrm{~h}$ after conditioning and infusion $\left(t_{(10)}=0.55 ; p>0.05\right)$ (Fig. $5 f$ ). LTM, assessed $24 \mathrm{~h}$ later, was also intact $\left(t_{(10)}=0.09, p>0.05\right)$ (Fig. $5 g$ ). Because both our CE and PRh infusion sites are approximately equidistant from the LA, this pattern of findings argues that the behavioral effects of intra-CE infusion of anisomycin are not likely attributable to spread of the drug from CE to LA. Rather, the results of these experiments imply that $\mathrm{CE}$, along with LA, is involved in, and possibly necessary for, the consolidation of fear memories. Future experiments will be required to more precisely define the intracellular signaling pathways that underlie synaptic plasticity and memory consolidation in the CE and to ask how these pathways might differ, if at all, from those known to underlie consolidation in the LA (Schafe et al., 2001).

\section{Discussion}

Early studies of the role of the amygdala in fear conditioning suggested that the CE was an essential site of the plasticity underlying fear conditioning (Applegate et al., 1982, 1983; Pascoe and Kapp, 1985; Kapp et al., 1990). Later anatomical, lesion, and electrophysiological studies redirected attention away from the CE to the LA, leading to the current model of amygdala involvement in emotional learning in which the association is encoded in the LA and in which CE functions solely as an output structure (LeDoux, 2000; Blair et al., 2001; Maren, 2001). Although the role of LA in fear learning and consolidation has been firmly established, we now show that functional inactivation of CE before fear conditioning disrupts fear learning and that protein synthesis inhibition in CE disrupts the consolidation of a fear memory. These findings provide new evidence to suggest that the $\mathrm{CE}$ is, like LA, a site of fear acquisition and memory storage.

Because the drugs used in our studies also affect fear learning, expression, and/or consolidation when infused into the LA, it was necessary to confirm that our infusions were restricted in their functional effects. Anticipating the possibility of spread, we used an even smaller infusion volume than that of several studies that have found behavioral effects on fear learning after infusion of small volumes of drugs into LA $(0.25-0.3 \mu \mathrm{l})$ but not after infusion of the same volumes into CE [bicuculline methiodide (Sanders and Shekhar, 1995); NBQX (2,3-dihydroxy-6-nitro-7sulfonyl-benzo[f]quinoxaline) (Walker and Davis, 1997); APV (Fanselow and Kim, 1994)]. Conversely, small infusions of muscimol $(0.1 \mu \mathrm{g} / \mu \mathrm{l} ; 0.25 \mu \mathrm{l})$ that are known to affect anxiety behaviors when infused into $C E$ are without effect when infused into LA (Sanders and Shekhar, 1995). These findings imply a lack of functional spread from one nucleus to another using the smaller infusion volumes. Next, we used a lower concentration than that used in many other studies (Helmstetter and Bellgowan, 1994; Sanders and Shekhar, 1995; Muller et al., 1997; Schafe and LeDoux, 2000; Wilensky et al., 2000; Bahar et al., 2003), including some that specifically investigate spread issues (Edeline et al., 2002; Maren et al., 2003). Collectively, these observations strongly imply that infusions at our dose and volume remain localized to CE. Our own experiments also support this conclusion. In our electrophysiological experiments, we observed no change in LA-evoked activity after infusion of a behaviorally effective dose of muscimol into CE. Perhaps most importantly, the behavioral effect of muscimol on fear learning was significantly larger after infusions into CE than when the same dose and volume was infused into LA. Together, these findings strongly suggest that spread from CE to LA cannot account for our findings. Rather, our experiments, as well as those of previous studies, imply that our findings are attributable to disruption of processes occurring in CE and not to the diffusion of drugs into LA.

The findings of the present experiment may appear to be at odds with a recent study that questioned the significance of CE in fear conditioning (Koo et al., 2004). In that study, pretraining electrolytic lesions of CE completely blocked contextual and auditory fear conditioning, whereas neurotoxic CE lesions had no effect on contextual fear and only moderately impaired auditory fear learning. It is unclear at present how to reconcile these findings with our own. One obvious difference between the two studies is that Koo et al. used permanent lesion methods, whereas we used reversible functional inactivation. Accordingly, it is possible that some compensatory rewiring of the fear circuit may have occurred during the week of recovery from the permanent lesions. Furthermore, it should be pointed out that our study has focused specifically on auditory fear conditioning, and the Koo et al. study did find impairments in auditory fear learning with both types of lesion (Koo et al., 2004). Finally, in our experiments, we used one to two tone-shock pairings, whereas Koo et al. used 10 tone-shock pairings. As a result, their unusually strong training protocol may have compensated for any incomplete neurotoxic lesions in their animals. Nevertheless, the clear differences exhibited between auditory and contextual fear conditioning in the Koo et al. study raise the intriguing possibility that CE manipulations differentially impair the acquisition and expression of auditory and contextual fear learning.

A number of outstanding questions remain to be asked about the precise nature of sensory information received by the $\mathrm{CE}$ and the critical sites of CS-US integration and plasticity. Although it is clear, for example, that the CE receives direct projections from regions of the posterior thalamus and posterior association cortex (LeDoux et al., 1985, 1987; Turner and Herkenham, 1991; McDonald, 1998; Linke et al., 2000), the extent to which these inputs are auditory as opposed to somatosensory is unclear (LeDoux et al., 1990a) and has not been thoroughly explored using physiological recording methods (for review, see Paré et al., 2004). Furthermore, the critical site of synaptic plasticity and memory formation within the CE also remains unknown. At least two divisions of the CE have been shown to receive overlapping projections from regions of the cortex and/or thalamus. Projections from the auditory thalamus and cortex, along with projections from the LA, terminate in the lateral division of the central nucleus (CEl), including the lateral capsular division (CEc or CeLC, depending on nomenclature) (Turner and Herkenham, 1991; Pitkanen et al., 1995; Jasmin et al., 1997; McDonald, 1998). The CEl and CEc are responsive to a variety of sensory stimuli (Bernard and Besson, 1990; Ono et al., 1995; Uwano et al., 1995) and also serve as the endpoint for nociceptive information relayed from the potine peribrachial nucleus (Bernard and Besson, 1990; Jasmin et al., 1997), making these regions well suited to integrate CS and US information during fear conditioning. In a recent paper, however, Paré et al. (2004) have argued that neurons in the CEl may not be appropriate as a site of plasticity of fear conditioning. This is attributable to the fact that they are primarily inhibitory $(\mathrm{McD}$ onald and 
a.

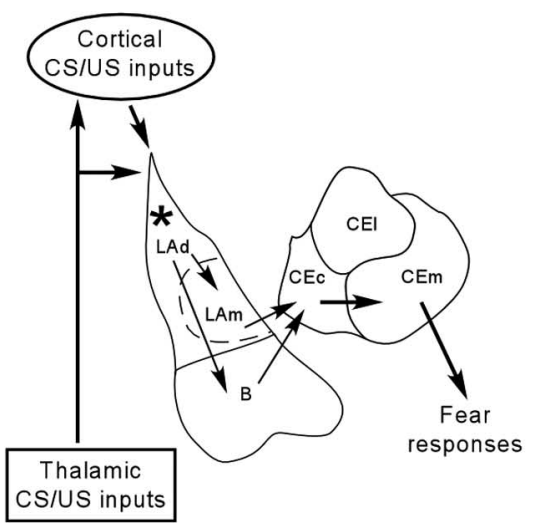

b.

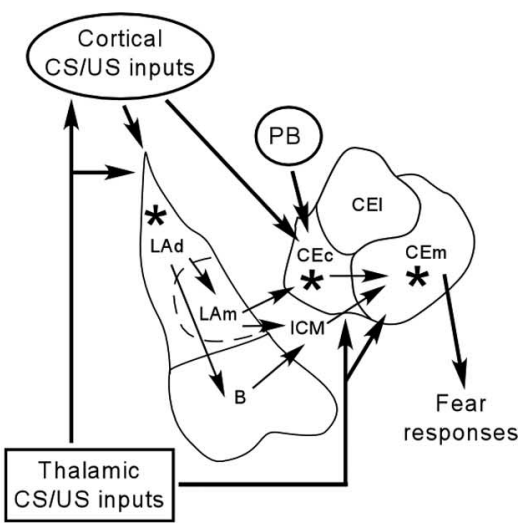

Figure 6. A revised model of the role of the amygdala in fear conditioning. $\boldsymbol{a}$, Original model. CS and US information travels through the thalamic and cortical pathways to converge in the dorsal LA. The information is then encoded in LA. During expression, sensory CS information is transmitted from LA to CE, both directly and by way of the adjacent basal nucleus (B). The CE is the major source of output pathways for fear responses such as freezing. $\boldsymbol{b}$, A new possibility. CS and US information are transmitted through multiple pathways to both the $L A$ and $C E$, resulting in plasticity and memory formation that is distributed within each of the nuclei. Auditory and somatosensory information originating in the thalamus may reach $\mathrm{CEm}$, the principle source of brainstem-projecting outputs from the CE, either directly or via the adjacent CEl. In addition, projections from the $L A$ may reach the CEm either via the CEl or via projections from the intercalated cell masses, which lie between the LA and CE. Convergence of sensory inputs in CEm results in synaptic plasticity and serves as an additional site of fear memory formation. It remains unclear, however, whether plasticity and memory formation in CE occurs in parallel to that in $L A$ or relies on distributed plasticity throughout the amygdala that is initiated by LA neurons. For additional details, see Paré et al. (2004). Asterisks indicate site(s) of presumed synaptic plasticity/learning. LAd, Dorsal division of the LA; LAm, medial division of the LA; PB, peribrachial nucleus.

Augustine, 1993; Paré and Smith, 1993a) and project only modestly to the medial division of the CE (CEm) (Paré and Smith, 1993b), the division of CE that provides the principal source of outputs to the brainstem autonomic centers that control fear responses (Hopkins and Holstege, 1978; Schwaber et al., 1982; Veening et al., 1984; LeDoux et al., 1988; Liubashina et al., 2000). The CEm, however, is also a recipient of projections from regions of the auditory thalamus (LeDoux et al., 1987; Turner and Herkenham, 1991; McDonald, 1998; Linke et al., 2000). Importantly, a recent study showed that high-frequency stimulation of the auditory thalamus induces an NMDAR-dependent LTP in CEm neurons (Samson and Paré, 2005). Furthermore, inputs from the LA can reach CEm via projections to the nearby intercalated cell (ITC) masses that lie between LA and CE (Paré and Smith, 1993b; Royer et al., 1999). Although ITCs are themselves inhibitory, they are known to be connected to one another in a lateromedial unidirectional manner (Royer et al., 2000). Accordingly, activation of an ITC just medial to the LA will inhibit another cluster of ITCs located more ventrally and medially, with the ultimate effect of disinhibiting CEm neurons (Royer et al., 1999). Collectively, these findings suggest that $\mathrm{CEc}, \mathrm{CEm}$, or both regions may serve as a critical site(s) of plasticity and memory storage in auditory fear conditioning (Fig. 6b). Additional experiments using single-unit recording techniques will be required to more precisely determine whether direct CS-US convergence from sensory processing regions takes place in these areas and to map the regions of the $\mathrm{CE}$ that encode associative memory formation during fear conditioning.

In summary, we have shown that CE plays an important role in the acquisition, consolidation, and expression of auditory pavlovian fear conditioning. These findings suggest that memory formation of fear conditioning is more distributed within the amygdala than previously appreciated (Fig. 6). However, although learning and memory in the amygdala may be distributed rather than localized, it remains unclear how the $\mathrm{CE}$ might participate in fear learning. Because the CE potentially receives both CS and US information, it is possible that CE is encoding in parallel the same type of CS-US association encoded by LA. This pattern of findings, however, would suggest that $\mathrm{CE}$ should readily be capable of mediating fear learning if the LA is compromised, a finding that is not supported by the literature. Another possibility is that plasticity in LA and CE proceeds in a serial manner, such that plasticity and memory formation in the CE depends on plasticity in the LA. In fact, one recent model proposes that plasticity in the LA enables CE to encode plasticity that is essential for fear conditioning, resulting in distributed plasticity and memory formation throughout the amygdala (Paré et al., 2004). Interestingly, a similar distributed model has also been proposed emphasizing LA-driven plasticity in the basal nucleus of the amygdala, a nucleus that until recently was thought to play little role in auditory fear conditioning (Anglada-Figueroa and Quirk, 2005). Furthermore, there is also evidence of a distributed network of plasticity within LA, with different subnuclei playing distinct roles in plasticity (Repa et al., 2001; Medina et al., 2002). These various studies and models emphasize the importance of a distributed view of amygdaloid plasticity, but future experiments will be necessary to determine the precise roles and interactions of the various regions and subregions of the amygdala in the acquisition and consolidation of fear conditioning.

\section{References}

Alberini CM, Ghirardi M, Huang YY, Nguyen PV, Kandel ER (1995) A molecular switch for the consolidation of long-term memory: cAMPinducible gene expression. Ann NY Acad Sci 758:261-286.

Amorapanth P, LeDoux JE, Nader K (2000) Different lateral amygdala outputs mediate reactions and actions elicited by a fear-arousing stimulus. Nat Neurosci 3:74-79.

Anglada-Figueroa D, Quirk GJ (2005) Lesions of the basal amygdala block expression of conditioned fear but not extinction. J Neurosci 25:9680-9685.

Applegate CD, Frysinger RC, Kapp BS, Gallagher M (1982) Multiple unit activity recorded from amygdala central nucleus during Pavlovian heart rate conditioning in rabbit. Brain Res 238:457-462.

Applegate CD, Kapp BS, Underwood MD, McNall CL (1983) Autonomic and somatomotor effects of amygdala central N. stimulation in awake rabbits. Physiol Behav 31:353-360.

Arikan R, Blake NM, Erinjeri JP, Woolsey TA, Giraud L, Highstein SM (2002) A method to measure the effective spread of focally injected muscimol into the central nervous system with electrophysiology and light microscopy. J Neurosci Methods 118:51-57.

Bahar A, Samuel A, Hazvi S, Dudai Y (2003) The amygdalar circuit that acquires taste aversion memory differs from the circuit that extinguishes it. Eur J Neurosci 17:1527-1530.

Bailey DJ, Kim JJ, Sun W, Thompson RF, Helmstetter FJ (1999) Acquisition of fear conditioning in rats requires the synthesis of mRNA in the amygdala. Behav Neurosci 113:276-282.

Bernard JF, Besson JM (1990) The spino(trigemino)pontoamygdaloid pathway: electrophysiological evidence for an involvement in pain processes. J Neurophysiol 63:473-490.

Blair HT, Schafe GE, Bauer EP, Rodrigues SM, LeDoux JE (2001) Synaptic plasticity in the lateral amygdala: a cellular hypothesis of fear conditioning. Learn Mem 8:229-242.

Cahill L, Weinberger NM, Roozendaal B, McGaugh JL (1999) Is the amygdala a locus of "conditioned fear"? Some questions and caveats. Neuron 23:227-228.

Campeau S, Davis M (1995) Involvement of the central nucleus and basolateral complex of the amygdala in fear conditioning measured with fearpotentiated startle in rats trained concurrently with auditory and visual conditioned stimuli. J Neurosci 15:2301-2311.

Doron NN, LeDoux JE (1999) Organization of projections to the lateral 
amygdala from auditory and visual areas of the thalamus in the rat. J Comp Neurol 412:383-409.

Doyère V, Schafe GE, Sigurdsson T, LeDoux JE (2003) Long-term potentiation in freely moving rats reveals asymmetries in thalamic and cortical inputs to the lateral amygdala. Eur J Neurosci 17:2703-2715.

Edeline JM, Hars B, Hennevin E, Cotillon N (2002) Muscimol diffusion after intracerebral microinjections: a reevaluation based on electrophysiological and autoradiographic quantifications. Neurobiol Learn Mem 78:100-124.

Fanselow MS, Kim JJ (1994) Acquisition of contextual Pavlovian fear conditioning is blocked by application of an NMDA receptor antagonist D,L2-amino-5-phosphonovaleric acid to the basolateral amygdala. Behav Neurosci 108:210-212.

Goosens KA, Maren S (2001) Contextual and auditory fear conditioning are mediated by the lateral, basal, and central amygdaloid nuclei in rats. Learn Mem 8:148-155.

Helmstetter FJ (1992) Contribution of the amygdala to learning and performance of conditional fear. Physiol Behav 51:1271-1276.

Helmstetter FJ, Bellgowan PS (1994) Effects of muscimol applied to the basolateral amygdala on acquisition and expression of contextual fear conditioning in rats. Behav Neurosci 108:1005-1009.

Hitchcock JM, Davis M (1991) Efferent pathway of the amygdala involved in conditioned fear as measured with the fear-potentiated startle paradigm. Behav Neurosci 105:826-842.

Hopkins DA, Holstege G (1978) Amygdaloid projections to the mesencephalon, pons and medulla oblongata in the cat. Exp Brain Res 32:529-547.

Jasmin L, Burkey AR, Card JP, Basbaum AI (1997) Transneuronal labeling of a nociceptive pathway, the spino-(trigemino-)parabrachio-amygdaloid, in the rat. J Neurosci 17:3751-3765.

Kapp BS, Frysinger RC, Gallagher M, Haselton JR (1979) Amygdala central nucleus lesions: effect on heart rate conditioning in the rabbit. Physiol Behav 23:1109-1117.

Kapp BS, Wilson A, Pascoe J, Supple W, Whalen PJ (1990) A neuroanatomical systems analysis of conditioned bradycardia in the rabbit. In: Learning and computational neuroscience: foundations of adaptive networks (Gabriel M, Moore J, eds), pp 53-90. Cambridge, MA: MIT.

Kim M, Davis M (1993) Electrolytic lesions of the amygdala block acquisition and expression of fear-potentiated startle even with extensive training but do not prevent reacquisition. Behav Neurosci 107:580-595.

Koo JW, Han JS, Kim JJ (2004) Selective neurotoxic lesions of basolateral and central nuclei of the amygdala produce differential effects on fear conditioning. J Neurosci 24:7654-7662.

LeDoux JE (2000) Emotion circuits in the brain. Annu Rev Neurosci 23:155-184.

LeDoux JE, Ruggiero DA, Reis DJ (1985) Projections to the subcortical forebrain from anatomically defined regions of the medial geniculate body in the rat. J Comp Neurol 242:182-213.

LeDoux JE, Ruggiero DA, Forest R, Stornetta R, Reis DJ (1987) Topographic organization of convergent projections to the thalamus from the inferior colliculus and spinal cord in the rat. J Comp Neurol 264:123-146.

LeDoux JE, Iwata J, Cicchetti P, Reis DJ (1988) Different projections of the central amygdaloid nucleus mediate autonomic and behavioral correlates of conditioned fear. J Neurosci 8:2517-2529.

LeDoux JE, Farb C, Ruggiero DA (1990a) Topographic organization of neurons in the acoustic thalamus that project to the amygdala. J Neurosci 10:1043-1054.

LeDoux JE, Cicchetti P, Xagoraris A, Romanski LM (1990b) The lateral amygdaloid nucleus: sensory interface of the amygdala in fear conditioning. J Neurosci 10:1062-1069.

Linke R, Braune G, Schwegler H (2000) Differential projection of the posterior paralaminar thalamic nuclei to the amygdaloid complex in the rat. Exp Brain Res 134:520-532.

Liubashina O, Jolkkonen E, Pitkanen A (2000) Projections from the central nucleus of the amygdala to the gastric related area of the dorsal vagal complex: a Phaseolus vulgaris-leucoagglutinin study in rat. Neurosci Lett 291:85-88.

Maren S (2001) Neurobiology of Pavlovian fear conditioning. Annu Rev Neurosci 24:897-931.

Maren S, Ferrario CR, Corcoran KA, Desmond TJ, Frey KA (2003) Protein synthesis in the amygdala, but not the auditory thalamus, is required for consolidation of Pavlovian fear conditioning in rats. Eur J Neurosci 18:3080-3088.

Martin JH (1991) Autoradiographic estimation of the extent of reversible inactivation produced by microinjection of lidocaine and muscimol in the rat. Neurosci Lett 127:160-164.

McDonald AJ (1998) Cortical pathways to the mammalian amygdala. Prog Neurobiol 55:257-332.
McDonald AJ, Augustine JR (1993) Localization of GABA-like immunoreactivity in the monkey amygdala. Neuroscience 52:281-294.

McGaugh JL, Ferry B, Vazdarjanova A, Roozendaal B (2000) Amygdala: role in modulation of memory storage. In: The amygdala: a functional analysis, Ed 2 (Aggleton JP, ed), pp 391-423. Oxford: Oxford UP.

Medina JF, Christopher Repa J, Mauk MD, LeDoux JE (2002) Parallels between cerebellum- and amygdala-dependent conditioning. Nat Rev Neurosci 3:122-131.

Muller J, Corodimas KP, Fridel Z, LeDoux JE (1997) Functional inactivation of the lateral and basal nuclei of the amygdala by muscimol infusion prevents fear conditioning to an explicit conditioned stimulus and to contextual stimuli. Behav Neurosci 111:683-691.

Nader K, Majidishad P, Amorapanth P, LeDoux JE (2001) Damage to the lateral and central, but not other, amygdaloid nuclei prevents the acquisition of auditory fear conditioning. Learn Mem 8:156-163.

Ono T, Nishijo H, Uwano T (1995) Amygdala role in conditioned associative learning. Prog Neurobiol 46:401-422.

Paré D, Smith Y (1993a) Distribution of GABA immunoreactivity in the amygdaloid complex of the cat. Neuroscience 57:1061-1076.

Paré D, Smith Y (1993b) The intercalated cell masses project to the central and medial nuclei of the amygdala in cats. Neuroscience 57:1077-1090.

Paré D, Quirk GJ, LeDoux JE (2004) New vistas on amygdala networks in conditioned fear. J Neurophysiol 92:1-9.

Pascoe JP, Kapp BS (1985) Electrophysiological characteristics of amygdaloid central nucleus neurons during Pavlovian fear conditioning in the rabbit. Behav Brain Res 16:117-133.

Paxinos G, Watson C (1997) The rat brain in stereotaxic coordinates: computer graphics files, compact Ed 3. San Diego: Academic.

Pitkanen A, Stefanacci L, Farb CR, Go GG, LeDoux JE, Amaral DG (1995) Intrinsic connections of the rat amygdaloid complex: projections originating in the lateral nucleus. J Comp Neurol 356:288-310.

Repa JC, Muller J, Apergis J, Desrochers TM, Zhou Y, LeDoux JE (2001) Two different lateral amygdala cell populations contribute to the initiation and storage of memory. Nat Neurosci 4:724-731.

Royer S, Martina M, Paré D (1999) An inhibitory interface gates impulse traffic between the input and output stations of the amygdala. J Neurosci 19:10575-10583.

Royer S, Martina M, Paré D (2000) Polarized synaptic interactions between intercalated neurons of the amygdala. J Neurophysiol 83:3509-3518.

Samson RD, Paré D (2005) Activity-dependent synaptic plasticity in the central nucleus of the amygdala. J Neurosci 25:1847-1855.

Sanders SK, Shekhar A (1995) Regulation of anxiety by GABAA receptors in the rat amygdala. Pharmacol Biochem Behav 52:701-706.

Schafe GE, LeDoux JE (2000) Memory consolidation of auditory pavlovian fear conditioning requires protein synthesis and protein kinase $\mathrm{A}$ in the amygdala. J Neurosci 20:RC96(1-5).

Schafe GE, Nader K, Blair HT, LeDoux JE (2001) Memory consolidation of Pavlovian fear conditioning: a cellular and molecular perspective. Trends Neurosci 24:540-546.

Schwaber JS, Kapp BS, Higgins GA, Rapp PR (1982) Amygdaloid and basal forebrain direct connections with the nucleus of the solitary tract and the dorsal motor nucleus. J Neurosci 2:1424-1438.

Shi CJ, Davis M (1999) Pain pathways involved in fear conditioning measured with fear-potentiated startle: lesion studies. J Neurosci 19:420-430.

Stevens CF (1994) CREB and memory consolidation. Neuron 13:769-770.

Turner BH, Herkenham M (1991) Thalamoamygdaloid projections in the rat:a test of the amygdala's role in sensory processing. J Comp Neurol 313:295-325.

Uwano T, Nishijo H, Ono T, Tamura R (1995) Neuronal responsiveness to various sensory stimuli, and associative learning in the rat amygdala. Neuroscience 68:339-361.

Veening JG, Swanson LW, Sawchenko PE (1984) The organization of projections from the central nucleus of the amygdala to brainstem sites involved in central autonomic regulation: a combined retrograde transportimmunohistochemical study. Brain Res 303:337-357.

Walker DL, Davis M (1997) Double dissociation between the involvement of the bed nucleus of the stria terminalis and the central nucleus of the amygdala in startle increases produced by conditioned versus unconditioned fear. J Neurosci 17:9375-9383.

Wilensky AE, Schafe GE, LeDoux JE (2000) The amygdala modulates memory consolidation of fear-motivated inhibitory avoidance learning but not classical fear conditioning. J Neurosci 20:7059-7066.

Young BJ, Leaton RN (1996) Amygdala central nucleus lesions attenuate acoustic startle stimulus-evoked heart rate changes in rats. Behav Neurosci 110:228-237. 